\title{
CONSOLIDAR O REALIZADO; IR PELO QUE FALTA: \\ ARQUEOLOGIA DAS DITADURAS MILITARES NA AMÉRICA DO SUL
}

Melisa A. Salerno ${ }^{1}$ e Andrés Zarankin ${ }^{2}$

RESUMO: Neste artigo refletimos criticamente sobre o desenvolvimento das investigações arqueológicas interessadas nas ditaduras militares na América do Sul. Para isso, centramos a atenção no caso argentino, tendo em vista sua história de políticas repressivas extremas; seu caráter pioneiro, abundante e diverso dos estudos sobre a temática, e a nossa própria experiência de trabalho, que possui cerca de 10 anos de duração. Inicialmente, discutimos a orientação que caracterizou os estudos, assim como os fatores sociais, políticos e acadêmicos que os impactaram. Posteriormente, apresentamos alguns desafios que o recorte tem apresentado, e ainda apresenta, aos investigadores.

Palavras-chaves: ditaduras militares, Américas do Sul, Argentina, arqueologia, reflexão crítica.

\section{DITADURAS MILITARES NA AMÉRICA DO SUL}

Em Março de 1964 as Forças Armadas do Brasil efetuaram um golpe de Estado, derrubaram o governo constitucional de João Goulart e colocarem em seu lugar Humberto de Alencar Castelo Branco. Em Junho de 1966 as Forças Armadas da Argentina depuseram Arturo Illia e designaram como presidente Juan Carlos Onganía. Em Novembro de 1964 as Forças

\footnotetext{
${ }^{1}$ Instituto Multidisciplinario de Historia y Ciencias Humanas. CONICET, Argentina. melisa_salerno@yahoo.com.ar

${ }^{2}$ Departamento de Antropologia e Arqueologia, UFMG, Brasil. zarankin@ yahoo.com
}

๔ Rev. Arqueologia Pública

\begin{tabular}{l|l} 
Campinas, SP & v.
\end{tabular}

No.()

p.72-98 $/ 2015$

ISSN 2237-8294 
Armadas da Bolívia instauraram no governo o general René Barrientos e depois de governos intermediários, com o golpe de Hugo Bánzer, em 1971, reorientaram a política do país em direção à extrema direita. Em Junho de 1973 o presidente constitucional do Uruguai, Juan Carlos Bordaberry, dissolveu o parlamento e criou um Conselho de Estado com participação das Forças Armadas. Em Setembro de 1973 o Chile sofreu um golpe que destituiu Salvador Allende e instaurou a Junta Militar presidida por Augusto Pinochet. Em Março de 1976 as Forças Armadas da Argentina depuseram María Estela Martínez de Perón, instauraram uma Junta e deixaram no comando Jorge Rafael Videla. E, em 1954, o Paraguai sofria com a extensa ditatura de Alfredo de Stroessner.

Para além da sucessão de fatos, nomes próprios, datas e países, o que queremos destacar é que, entre as décadas de 1960 e 1970, as ditaduras ganharam força na América do Sul, especialmente no Cone Sul. Como em qualquer estado de exceção, os regimes foram instaurados por golpes de Estado. Os militares desempenharam um papel protagonista, contando ocasionalmente com a participação de autoridades civis. Os novos governos não só dissolveram os parlamentos como também impuseram leis marciais. Fundamentados na aparente necessidade de enfrentar estados de emergência, limitaram e/ou suspenderam liberdades civis básicas.

Mantendo vínculos com o fascismo, as ditaduras sul-americanas do período considerado tiveram um caráter próprio e se distanciaram das ditaduras de momentos prévios (MAIRA, 1990). Os regimes ditatoriais do século XIX e da primeira metade do século XX se desenvolveram a partir de economias rurais, em um contexto onde a atuação política era entendida como privilégio exclusivo das elites. De modo geral, se organizaram em torno de

$\Re$ figuras individuais e não contavam com um projeto nacional de grande prazo, uma

\begin{tabular}{|l|l|l|l|l|l|l|}
\hline () Rev. Arqueologia Pública & Campinas, SP & v. & No.() & p.72-98 & /2015 & ISSN 2237-8294 \\
\hline
\end{tabular}


colaboração internacional de envergadura e/ou com uma organização sistemática da repressão.

Nas décadas de 1960 e 1970, as ditaduras surgiram em um contexto de crescente industrialização e urbanização, que presumiu reivindicações por parte dos novos setores. Desde a Revolução Cubana, os movimentos de esquerda experimentaram um forte crescimento (AVELAR, 1999). Seu desenvolvimento se manifestou no descontentamento e na organização de grupos campesinos e obreiros, e no aumento das greves e manifestações, entre outros aspectos. Em alguns casos, os partidos de esquerda alcançaram posições significativas nas eleições democráticas e, em outros, recorreram as resistências armadas (WRIGHT, 2007).

As ditaduras citadas participaram de um cenário internacional complexo. Desde a década de 1940 o Estado Unido elaborou sua "Doutrina de Segurança Nacional”. Em plena Guerra Fria, em um contexto no qual o mundo se debatia entre dois sistemas irreconciliáveis, o crescimento do comunismo foi percebido como uma ameaça ao capitalismo. Reconhecendo que formavam parte de um mundo interconectado, os norte-americanos entenderam como fundamental controlar a presença da esquerda na América do Sul. Assim, sua política externa oferecia formas de apoio aos regimes anticomunistas (GILL, 2004).

As ditaduras sul-americanas encontraram na segurança nacional um discurso legitimador. A esquerda foi apresentada como um inimigo atual e latente, capaz de se infiltrar nos setores mais inesperados da sociedade. A repressão subentendeu persuasão ideológica, censura e exílio. O desaparecimento forçado foi uma estratégia privilegiada (UNITED NATIONS, 2006). O procedimento comumente implicava "marcar" uma pessoa; sequestrá-la por intermédio de um comando paramilitar do próprio Estado e encaminhá-la a um centro de detenção 


\section{ATAS}

clandestino. Daí por diante, os próximos passos eram: interrogatório, tortura e, ocasionalmente, assassinato e ocultamento de restos.

É possível que as semelhanças nas estratégias repressivas dos distintos países se vincularam com a formação dos oficiais na Escola das Américas (dirigidas pelos Estados Unidos) e na Escola Superior da Guerra da França (onde se ensinava táticas de contra insurgências desenvolvidas na Argélia). Sem lugar para dúvidas, as semelhanças também se conectaram com o desenvolvimento de uma estratégia combinada entre os Estados. De acordo com documentos desclassificados, em 1975, se implementou uma campanha de repressão de abrangência política regional: o denominado "Plano Cóndor" (NILSON, 1998). Este plano incorporou países como Argentina, Brasil, Chile, Bolívia, Uruguai e Paraguai; e contou com o apoio dos Estados Unidos (MCSHERRY, 2002).

A Bolívia abandonou a ditadura em 1982, a Argentina em 1983, o Brasil em 1984, o Uruguai em 1985 e o Paraguai e o Chile em 1989. O desmoronamento dos regimes não dependeu de processos revolucionários abruptos, mas, especialmente, de fatores de longa duração. Desde fins da década de 1970 os regimes começaram a experimentar crises econômicas, políticas e sociais como resultado de medidas pesadas. Ademais, o fim da Guerra Fria impediu que os militares continuassem impondo o terror ao comunismo como principal justificativa de sua presença (RICO, 1997).

Com o retorno da democracia, os familiares das vítimas e as organizações de direitos humanos fizeram ouvir suas exigências sobre os excessos cometidos nas ditaduras. Os militares tentaram ocultar as evidências de seus crimes. Deste modo, desmantelaram os centros de detenção clandestinos, mantiveram em segredo os destinos dos corpos e destruíram documentos sobre suas operações ilegais (entre outros). Apesar dos testemunhos 
dos sobreviventes, diversos aspectos da repressão permaneceram desconhecidos. Foi nesse necessário que a arqueologia começou a se envolver nas investigações (FUNARI et al., 2009).

\section{O CASO DA ARGENTINA}

Neste artigo realizamos uma reflexão crítica sobre o desenrolar das investigações arqueológicas interessadas nas ditaduras militares da América do Sul. Para isso, centramos a atenção no caso da Argentina. O motivo desta escolha respondeu a diversos fatores. Em primeiro lugar, a ditadura militar no país definiu-se por uma política repressiva extrema, caraterizada pela magnitude de seu aparato clandestino e grande saldo de vítimas. Entre 1976 e 1982, o autodenominado "Processo de Reorganização Nacional" deteve, de maneira ilegal, centenas de milhares de pessoas em 500 lugares secretos (FERNÁNDEZ MOORES, 2006). Tendo em conta as denúncias registradas, se estima que mais de 9.000 pessoas foram assassinadas e seus restos foram ocultados (CONADEP, 1984).

Porém, a aspereza das políticas repressivas não foi o único fator pelo qual decidimos analisar o caso da Argentina. Entre os motivos, encontra-se o fato do país ter se tornado pioneiro e constante dizimador das investigações arqueológicas interessadas pelas ditaduras e suas consequências na região. Apesar disso, ao menos até o presente, constituiu o cenário onde se levaram a frente a maior quantidade e diversidade de estudos em torno da temática.

Em terceiro lugar, a Argentina é o caso em que temos trabalhado a cerca de 10 anos, logo, refletir sobre a trajetória das investigações no país também nos oferece possibilidade de nos perguntarmos sobre os alcances e limitações de nossas próprias contribuições nesse campo de estudo. 
Nos próximos dois subitens analisamos o desenvolvimento das investigações arqueológicas acerca da ditadura militar Argentina. No primeiro, discutimos as orientações dos trabalhos ao longo do tempo (objetivos, interesses e marcos teórico-metodológicos), assim como os fatores sociais, políticos e acadêmicos que os impactaram. No segundo, debatemos os desafios que esses eventos apresentaram, e ainda apresentam, aos investigadores.

\section{O feito}

O retorno da democracia e os estudos forenses

Em 1982, depois do fracasso militar das Malvinas, a Quarta Junta Militar iniciou um processo de transição democrática. Tendo convocado as eleições em 1983, assumiu como presidente constitucional Raúl Alfonsín, o qual, imediatamente, decretou a abertura dos juízes das Juntas e as organizações guerrilheiras que tinham cometido crimes de lesa humanidade durante a década de 1970. A lei argentina estipulou que os membros das Forças Aramadas deviam ser processados por tribunais militares. Apesar disso, os casos, terminaram sendo transladados a uma corte civil, colocando um precedente a nível internacional (MALCONTENT e HEPPING, 2009).

Para investigar os desaparecimentos forçados, o governo criou a Comissão da Verdade CONADEP. As provas materiais analisadas consideraram os centros como clandestinos. Não obstante o registro dos lugares não contar com arqueólogos, esta foi uma primeira aproximação à sua materialidade. Em relação aos corpos dos desaparecidos, a CONADEP manteve uma posição ambígua: evitou assinalar de maneira explícita quem estava morto, porém apresentou testemunhos sobre possíveis enterramentos ilegais e deu conta das 
primeiras exumações (COHEN SALAMA, 1992). Nelas se tornou claro que os familiares desconfiavam da polícia e dos médicos forenses (que haviam sido funcionários da ditadura) e que estes profissionais careciam de experiência para exumar e analisar restos esqueletais (SALADO e FONDEBRIDER, 2008).

A busca dos corpos se transformou em prioritária. Em 1984 o CONADEP e as Mães da Praça de Maio convocaram uma equipe de profissionais internacionais. Clyde Snow, um reconhecido antropólogo forense, efetuou um chamado aos arqueólogos, antropólogos e médicos do país para receberem treinamento (JOYCE e STOVER, 1991), porém, só responderam estudantes jovens. Finalmente, alguns deles formaram a Equipe Argentina de Antropologia Forense EAAF (FONDEBRIDER, 2006). Diferente da antropologia forense clássica, que considerava um dano que o indivíduo efetuou ao outro de forma particular, a nova antropologia considerava o dano que o Estado havia provocado em uma parte importante de seus cidadãos (SOMIGLIANA, 2012). Como uma forma de manter a independência com respeito a um Estado que se apresentava como vítima, o EAAF se constituiu como uma organização nãogovernamental.

Geralmente, se diz que os arqueólogos profissionais se mantiveram às margens da convocatório de Snow pela viva recordação da perseguição aos intelectuais. Contudo, cabe considerar que a participação neste tipo de projeto desafia os pressupostos da arqueologia acadêmica do período (SALERNO et al., 2013). Por um lado, a maior parte dos arqueólogos entendia que a disciplina se preocupava com o passado distante, antes que com o presente ou o passado recente. Além disso, os acadêmicos não se reconheciam como sujeitos com um compromisso social e político. Por último, vale a pena recordar que alguns arqueólogos da época também haviam mantido certas afinidades com a ditadura.

( Rev. Arqueologia Pública

\begin{tabular}{l|l} 
Campinas, SP & v.
\end{tabular}

No.()

p.72-98 $/ 2015$

ISSN 2237-8294 
A antropologia forense levou adiante investigações de caráter legal. Neste marco, os membros do EAAF deveriam manter um vínculo estreito com a justiça, apontando provas, atuando como peritos e prestando testemunhos (FEDERACIÓN ESTATAL DE FOROS DE LA MEMORIA, 2009). Ainda que a antropologia forense pressupunha que os arqueólogos participassem em causas sociais e politicamente comprometidas, os requisitos da justiça demandaram que não abandonasse 0 ideal de objetividade nas investigações. A busca e a análise dos corpos mantiveram, assim, um caráter técnico, principalmente associado ao modelo das ciências positivistas.

A antropologia forense depende de uma combinação de metodologias provenientes da criminalística, do trabalho de campo arqueológico e da antropologia biológica. Nos últimos anos utilizou-se das análises genéticas (SOMIGLIANA e OLMO 2002). Assim, não só se decidiu por pegar amostras dos tecidos, como também de sangue dos familiares. Se bem que, inicialmente, as amostras eram coletadas em alguns casos individuais onde já existia uma hipótese de identidade, logo se efetuaram coletas maiores. Desde 2008 a "Iniciativa LatinoAmericana para a Identificação de Pessoas" produziu resultados exitosos (EAAF, 2008). Os dados disponíveis até 2013 assinalam que a EAAF tinha identificado mais de 500 corpos, tendo em resguardo outros 700 que necessitavam de estudos mais aprofundados (PEROSINO, 2012).

Sintetizando, é no trabalho da EAAF onde se pode rastrear os primeiros antecedentes de uma arqueologia da ditadura na Argentina. Por distintos fatores, incluindo o desinteresse da arqueologia tradicional, o caráter legal das investigações, a conformação do EAAF como ONG e a necessidade de resguardar dados sensíveis; a antropologia forense se manteve à margem do mundo acadêmico durante anos. Os principais motivos são: primeiro, os membros da EAAF publicaram a maior parte de seus trabalhos em informes anuais da instituição, antes que em 
publicações científicas tradicionais; segundo, a antropologia forense não foi incluída, e ainda não se inclui, no currículo da maior parte das universidades do país (recentemente, a partir de 2000, começaram a ocorrer seminários esporádicos na Universidade de Buenos Aires e em 2008 se inaugurou o doutorado em antropologia forense da Universidade Nacional de Córdoba); e terceiro, os organismos de ciência e técnica do país não participaram das tarefas de busca e identificação dos desaparecidos. A partir de tudo isso, construiu-se uma falsa contraposição entre uma arqueologia comprometida, do tipo não acadêmica, e uma arqueologia asséptica, inserida na academia.

A reabertura dos julgamentos e os estudos sobre centros clandestinos de detenção

O processo iniciado com a abertura dos julgamentos sofreu um retrocesso nos anos seguintes. Em 1986 e 1987, durante o próprio governo de Alfonsín, se firmaram as leis de obediência devida e ponto final, estabelecendo o confisco das ações penais contra os responsáveis dos desaparecimentos forçados e diagnosticando a impossibilidade de punir os subordinados (LA NACIÓN, 2005a, 2005b). Posteriormente, em 1989 e 1990, o presidente Carlos Menem indultou militares e civis previamente sentenciados como parte de um suposto projeto de reconciliação nacional (ÁLVAREZ, 2007). Neste contexto, e não sem dificuldades, o foco das investigações se manteve nas vítimas e não avançou sobre a lógica operativa dos crimes (que podia ser comprometida através de outras materialidades).

Na década dos anos 2000, especialmente sob o governo de Néstor Kirchner, inaugurou-se uma política estatal de memória, verdade e justiça. Se declarou a nulidade das leis de obediência devida e ponto final e se estabeleceu a inconstitucionalidade dos indultos. Reabriram-se os julgamentos, agora exclusivamente orientados contra o regime militar 
(FAULK, 2013). Alguns centros foram expropriados, transformando-se em espaços para a memória. O Estado e as organizações de direitos humanos procuraram os arqueólogos para efetuarem escavações. O principal objetivo era obter evidências materiais sobre a existência das prisões secretas; especialmente quando haviam sido destruídas como uma estratégia de ocultamento.

O interesse dos arqueólogos pela ditadura, agora atento aos ex-centros de detenção, também dependeu de uma série crise de mudanças operadas no interior da disciplina (SALERNO et al., 2013). Primeiro: a arqueologia se libertou dos limites temporais que a circunscreviam, o que resultou coincidente com o fortalecimento das arqueologias históricas. Segundo: os profissionais entenderam que era impossível ignorar sua própria subjetividade. Antes que uma limitação, o compromisso social e político começou a ser prensado como um valor produtivo. Terceiro: o poder, a dominação, a resistência e a agência se transformaram em temas relevantes. Quarto: os trabalhos passaram a considerar os setores sociais anteriormente marginalizados pelas narrativas oficiais. Quinto: os profissionais aceitaram que o conhecimento científico era uma das tantas formas de saberes existentes, democratizando a produção e incluindo outros autores.

Os projetos pioneiros nos ex-centros clandestinos incluíram trabalhos no ex-Clube Atlético (na cidade de Buenos Aires - WEISSEL, 2002; BIANCHI VILLELLI e ZARANKIN, 2003), no Maisión Seré (na província de Buenos Aires - Dirección do DDHH/Município de Morón, 20022003/2006-2008) e no Pozo (na cidade de Rosário, Província de Santa Fé - Centro Popular da Memória, 2003). A partir destas experiências, os projetos se multiplicaram significativamente. Não apenas se realizaram escavações de estruturas e objetos como também os antropólogos forenses efetuaram buscas de corpos nestes lugares. Até então, as tarefas haviam se concentrado nos cemitérios públicos; especialmente nas áreas destinadas a 
"NN", onde se considerava que haviam sido enterrados a maior parte dos desaparecidos. Como resultado, pode-se dizer que até a presente data, se efetuaram mais de 20 intervenções no ex-centros.

Para além dos trabalhos forenses, que falamos no ponto anterior, os estudos arqueológicos interessados nos ex-centros responderam a dois perfis: a maior parte deles apresentou um caráter técnico; ainda que alguns outros, apesar de levarem adiante este tipo de tarefa, também possuíam um enfoque interpretativo. Os trabalhos técnicos foram frequentes nos projetos relacionados, tendendo a responder solicitações da justiça. Assim, os arqueólogos se comprometem a atuar como peritos, proporcionando informação sobre as escavações. Por sua parte, os trabalhos interpretativos se desenvolveram no marco de projetos de maior envergadura, usualmente conectados com a gestão dos espaços da memória. Nesse sentido, articularam o trabalho de autoridades estatais, organizações de direitos humanos e investigadores de distintas especialidades.

Os trabalhos interpretativos discutiram as formas em que a materialidade dos centros modelou e foi modelada por uma dinâmica específica. A arquitetura foi um dos temas que mais interesse despertou. Em 2006, Zarankin e Niro (2006) elaboraram uma proposta para a análise do Clube Atlético, que logo foi retomada por numerosos investigadores. Nessa perspectiva, a arquitetura dos ex-centros revelou os mecanismos empregados pelos militares para destruir as identidades de suas vítimas. O trabalho se fundamentou nas ideias de poder do pensamento foucaultiano e utilizou os modelos de Hillier e Hanson (1984) para abordar os espaços internos. Com base nessas fundamentações, Zarankin e Niro (2006) entenderam que a arquitetura dos centros promovia a desumanização das pessoas e possuía elementos conectados com o panoptismo, ostentando uma estrutura não-destributiva e amplamente compartimentada, que permitia o controle.

(C) Rev. Arqueologia Pública

\begin{tabular}{l|l} 
Campinas, SP & v.
\end{tabular}

No.()

\begin{tabular}{l|l} 
p.72-98 & $/ 2015$
\end{tabular}

ISSN 2237-8294 
Zarankin y Niro (2006) consideraram alguns aspectos da resistência e da experiência nos excentros. Estes problemas foram aprofundados por alguns outros projetos. Há alguns anos, os investigadores do D2 de Córdoba começaram a analisar uma serie de marcas deixadas pelos presos nas celas (UNIVERSIDAD NACIONAL DE CÓRDOBA, 2007). Considerando a proposta de Navarrete (2006), seria possível entender que estas mensagens formam parte de um intento por suportar ou transcender condições de vida extremas. Além disso, a Equipe de Investigação pela Memória Político-Cultural considerou os sentidos e emoções que o excentro de detenção do Pozo pudesse despertar no passado e no presente (quando os sobreviventes reviveram o sucedido, os arqueólogos enfrentaram a materialidade das ruínas e os visitantes recorreram os espaços - BIANCHI et al., 2009).

O número de trabalhos interessados em compreender a rolagem de objetos nos ex-centros tem sido menor. Em 2007, Salerno (2007) discutiu as formas nas quais os militares transformaram a indumentária em uma ferramenta útil para a repressão. Retomando ideias de Foucault (1976), Goffman (2003) e outros autores, Salerno assinalou que os discursos da ditadura construíram um estereótipo em torno da aparência dos "subversivos" que encorajou a caça às bruxas. Assim mesmo, considerou que a indumentária desempenhou um papel protagonista nos ex-centros. A negação inicial do vestir buscou desestruturar as identidades, promover a humilhação e facilitar a tortura. A entrega de novas roupas aprofundou o impacto sobre as identidades. O uso de algemas e capuzes aumentavam a sensação de desproteção e os faziam sentirem-se como objetos imóveis e a mercê dos outros. Finalmente, muitos condenados foram obrigados a mudar com o propósito de forjar a causa da morte e dificultar sua identificação.

$\infty$
$\infty$
0
$\pi$
0
0 Resulta interessante destacar que alguns projetos têm decidido explorar o potencial dos objetos para construir memórias. Assim, os materiais são apresentados em exposições 
públicas onde podem ser contemplados pelos visitantes. Em alguns casos, os artefatos são recuperados pelos arqueólogos durante as escavações dos centros. Em outros, são doados pelos sobreviventes, familiares e outras pessoas (que não necessariamente foram detidos ou desaparecidos e nem alegavam o mesmo) - ver, por exemplo, MEMORIA ABIERTA, n/d. Os materiais permitem criar um laço entre o passado e o presente, estimulam a discussão sobre a vida na ditadura, as consequências do terrorismo do Estado, a identificação com as vítimas e suas histórias de vida, etc.

Sintetizando, os estudos conduzidos em torno dos ex-centros clandestinos inauguraram uma segunda etapa das arqueologias da ditadura na Argentina. Apesar de algumas resistências iniciais, onde os arqueólogos tradicionais assinalaram que o realizado "não era arqueologia", as mudanças realizadas no interior da disciplina estimularam a participação de diversos profissionais. A temática conseguiu instalar-se pela primeira vez no campo acadêmico. Não apenas formularam-se perguntas de investigação que excederam o rol técnico da arqueologia, mas também se organizaram mesas em congressos, publicações com colegas de outros países (ver, por exemplo, FUNARI et al., 2009; ZARANKIN et al., 2012), e inclusive, seminários em universidades. Porém, grande parte deste processo dependeu de iniciativas individuais de alguns investigadores. Frequentemente, os organismos da ciência e técnica se mantiveram à margem destes projetos e os investigadores que trabalhavam nos mesmos desenvolveram suas investigações à margem de outras tarefas.

A reescrita da história oficial e a abordagem dos espaços para a memória

Em nosso caso, até 2010, uma parte importante dos nossos trabalhos foi sobre arqueologia da ditadura, o que nos permitiu acumular uma serie de experiências como profissionais e 
cidadãos. Andres Zarankin recordava que em 2002, enquanto participava do projeto conduzido no ex-Clube Atlético, considerou necessário abrir o sítio à comunidade. Porém, tendo em vista as condições impostas pelo governo da Cidade de Buenos Aires, assim como a experiência com este trás vários meses de trabalho, os arqueólogos começaram a se perguntar se, para além dos sobreviventes e familiares, o capital simbólico do projeto não estava sendo manipulado em função dos interesses de setores do Estado. Os recursos econômicos eram mínimos e a maior parte dos pedidos para resolver problemas cotidianos eram ignorados. A suposta busca pela verdade e justiça pareciam estar respondendo a outros interesses, longe dos que como arqueólogos tínhamos pensado para ajudar as vitimas do terrorismo de Estado.

O ex-Clube Atlético não foi o único lugar oficialmente transformado no espaço para a memória da cidade de Buenos Aires. O Estado nacional e municipal elaborou diversos projetos ao longo do tempo e desde a década de 1990 declarou e/ou construiu um número significativo de espaços oficiais. Enquanto cidadãos, comumente os transitamos ou o percorremos. Tratavamse de lugares heterogêneos: ex-centros clandestinos (que sofreram ou não, intervenção arqueológica), parques, praças, placas comemorativas, etc. Tendo em vista sua diversidade, começamos a refletir: que tipo de histórias sobre o passado recente do país dava forma a materialidade desses sítios? Os lugares se encontravam em condições de cumprir com os objetivos que oficialmente Ihes haviam sido atribuídos? Que desafio ético subentendia sua construção e/ou gestão? O que nos ensinavam a construção da memória material no presente? (SALERNO e ZARANKIN, 2015).

A história dos espaços para a memória de Buenos Aires remonta a ditadura. Os primeiros espaços foram criados espontaneamente, como a ronda das Mães da Praça de Maio (CALVEIRA, 1998) ou o Siluetazo, durante o qual se "empapelaram" as ruas da cidade com 
silhuetas que representavam os desaparecidos (LONGONI e BRUZZONE, 2008). Com o passar do tempo, alguns desses espaços foram institucionalizados e outros foram construídos. A participação do Estado foi debatida. Alguns grupos de sobreviventes e vítimas se interessaram pelo reconhecimento oficial de suas memórias, enquanto outros consideraram necessário manter sua independência. Apesar disso, o Estado se mostrou decidido a criar uma nova história oficial sobre a ditadura e suas consequências.

Através de um levantamento efetuado em 2009 (ZARANKIN e SALERNO, 2012), percebemos que os ex-centros clandestinos, oficialmente reconhecidos como espaços para a memória na cidade de Buenos Aires, eram bastante numerosos. Além disso, se encontravam amplamente distribuídos e tinham boa visibilidade, construindo uma narrativa clara sobre o que alguma vez se manteve simultaneamente oculto e visível. A visita aos seus interiores tornava-se comovedora, estimulando reflexões sobre o cativeiro, a tortura e a morte. As ex-prisões clandestinas estabeleciam uma relação direta com o passado por estarem localizadas nos mesmos lugares onde ocorreram essas ações.

Além dos ex-centros clandestinos, alguns espaços para a memória tinham sido construídos durante a democracia, como o Parque da Memória e "outros sítios" (sensu INSTITUTO ESPACIO PARA LA MEMORIA, 2007), incluindo pequenas praças e placas comemorativas. $O$ Parque da Memória, ainda que não parecesse surpreender do seu exterior, oferecia uma experiência particular para quem o percorria. A infinidade de placas com nomes de vítimas, colocadas sobre paredes extensas em zigzagues, criavam uma narrativa efetiva sobre as dimensões do "genocídio". Os "outros lugares", se bem numerosos, compartilhavam uma invisibilidade generalizada. Muitos estavam mal sinalizados e na sombra das obras de maior destaque. Assim, tinham poucas chances de criar uma narrativa efetiva sobre o sucedido na ditadura.

(๐ Rev. Arqueologia Pública

\begin{tabular}{l|l} 
Campinas, SP & v.
\end{tabular}

No.()

p.72-98 $/ 2015$

ISSN 2237-8294 


\section{ATAS}

Os espaços para a memória da cidade foram resultado de diversas políticas. O ex-centros clandestinos se transformaram em lugares de comemoração mediante projetos coletivos que não apenas integraram os representantes do Estado, mas também sobreviventes, familiares de vítimas, organizações de direitos humanos, investigações, etc. A institucionalização dos lugares se desenvolveu em um contexto de mudança, onde as referências da justiça sugeridas pelas narrativas materiais se viram finalmente acompanhadas pelos julgamentos. As condições dos sítios, sem dúvida, também testemunhavam as dificuldades de sua gestão: atividades canceladas, falta de manutenção, espaços inacessíveis para a comunidade, falta de pessoal, manipulações políticas, etc.

Diferente dos ex-centros clandestinos de detenção, o Parque da Memória surgiu como expressão de resistência durante o período em que o poder executivo tentou estabelecer, nesse mesmo lugar, um monumento para a reconciliação nacional, fazendo-se omisso a possibilidade de fazer justiça (os julgamentos estavam suspensos e já havia se firmado os direitos de perdão). Entretanto, os "outros lugares" não foram produto de um trabalho coletivo. Alguns foram criados em fins da década de 1990 e em um número importante de casos pareciam ser parte de uma política que considerou mais fácil construir placas do que se comprometer efetivamente com a memória e a justiça.

\section{O que falta}

O estudo dos espaços para a memória não deixou claro que a materialidade envolvia tensões presentes e passadas em torno da abordagem da ditadura e suas consequências. Este tipo de trabalho marcou, no nosso entendimento, uma terceira etapa das arqueologias da ditadura na Argentina, orientando-nos a refletir criticamente sobre nosso próprio trabalho como 
profissionais. A pergunta subjacente passou a ser: que tipo de histórias estamos ajudando a construir sobre o passado recente e o presente do país? De nossa perspectiva, se tornou necessário perder a ingenuidade. Talvez nossos discursos tenham sido um tanto lineares, homogêneos e triunfalistas; negando a multidimensionalidade de uma problemática que interseccionava uma diversidade de atores, interesses, pontos de encontro e, inclusive, conflitos e lutas.

$\mathrm{Na}$ continuação, oferecemos alguns exemplos que, embora não sejam formalmente expostos, apresentam de maneira latente uma série de desafios que não devemos ignorar. Pensemos, por exemplo, no trabalho dos antropólogos forenses. Na maior parte dos casos, os trabalhos dão por certo que todos os familiares dos desaparecidos estão interessados na busca, exumação, análises e restituição de seus restos. Contudo, os familiares mostram uma diversidade de posições a respeito. Aqui vale a pena considerar o caso das Mães da Praça de Maio. Os debates que se geraram em torno da problemática foram uma das causas de sua divisão no passado.

A linha das Mães liderada por Hebe de Bonafini se encontra fundada no slogan "Aparição com vida", e, portanto, rejeita as exumações, as restituições e as comemorações post-mortem. Entretanto, a linha "Fundadora" das Mães da Praça de Maio considera que as investigações forenses são essenciais como prova dos delitos cometidos pela ditadura (ainda que algumas das mães não estão particularmente interessadas em recuperar os corpos). Esta posição também é compartilhada por distintas pessoas e por distintas razões, incluindo o impacto emocional que envolvem os procedimentos (PEROSINO, 2012).

Desde 1984 o trabalho da EAAF tem permitido exumar, analisar e identificar centenas de corpos. Entre eles, se encontram indivíduos cujos familiares anseiam encontrar seus restos, e outros que não. Enquanto os últimos familiares não haviam doado DNA para confrontar as

(๐ Rev. Arqueologia Pública

\begin{tabular}{l|l} 
Campinas, SP & v. \\
\hline
\end{tabular}

No.()

p.72-98 $/ 2015$ ISSN 2237-8294 
amostras esqueletais, o certo é que em muitas ocasiões foi possível reconstruir identicidades individuais como resultado de sua inclusão em conjuntos de corpos, que simultaneamente estavam relacionados por "linhas de pesquisa sobre desaparecimento" (data de desaparecimento, sequestro em um mesmo centro clandestino, data de "translado", etc.). Além disso, ainda que o processo de identificação no EAAF continue avançando, existem restos que por sua condição de queimados, fragmentados e outros, talvez nunca serão identificados. À estes também teriam que se agregar os identificados que não podem ser restituídos porque seus familiares, embora estivessem interessados nos restos, tenham falecido. Que faremos, então, com estes restos que ninguém reclamou? Os colocaremos em uma sorte de panteão comum? Esta é uma das questões que seguramente nos debateremos nos próximos anos.

Pensamos, também, na forma em que os arqueólogos entenderam as vítimas da repressão quando estudaram os ex-centros clandestinos. No geral, nos referimos a eles simplesmente como "desaparecidos", figuras aparentemente homogêneas através das quais todos os afetados poderiam identificarem-se (o que apresenta certos pontos de contato com as representações do "Siluetazo"). Não devemos esquecer que o arquétipo dos "desaparecidos" tem sido frequentemente ligado com uma pessoa masculina e jovem. Além disso, nos discursos produzidos pelos arqueólogos, existiu uma negação de suas histórias de militância política. Enquanto a noção de "desaparecidos" tem sido importante na luta política, é certo que também tem dificultado compreender a diversidade de atores e experiências vividas nos centros clandestinos. Sem dúvida, para quem esteve detido, não foi o mesmo ser homem, mulher, jovem, velho, militante (ou não) de algum movimento político (BIANCHI et al., 2012). Neste contexto, não queremos deixar de mencionar que o reconhecimento da militância dos atores não deve colocar em dúvida, de nenhuma maneira, sua condição de vítimas.

(C) Rev. Arqueologia Pública

Campinas, SP $\mathrm{v}$.

No.()

\begin{tabular}{l|l} 
p.72-98 & $/ 2015$
\end{tabular} ISSN 2237-8294 
Pensando nas categorias discursivas, gastaríamos de nos ater as formas em que nossas referências aos direitos humanos têm focado, quase exclusivamente, nas vítimas de desaparecimento forçado durante a ditadura. De maneira consciente ou não, esta forma de categorização tem criado uma nova esfera de excluídos e invisibilidades desses mesmos direitos que se pretendem universais (sensu BUTLER, 2002). Entre eles se encontram as vítimas de conflitos passados e presentes, que nem sempre tem recebido igual importância na agenda nacional. $\mathrm{Na}$ atualidade, esses mesmos grupos se encontram lutando por reconhecimento. Se apropriam e resignificam as táticas desempenhadas no passado, para as vítimas da ditadura, para recuperar suas identidades e memórias. Como podem os arqueólogos colaborar nesses processos de diálogo entre diversos processos de violação dos direitos humanos?

Ainda falta muito por percorrer. Porém, aqui trazemos como exemplo um projeto que está sendo realizado pela colega argentina María Celeste Perosino, no marco da ONG Ações Coordenadas contra o tráfico - ACCT. Seu objetivo é colaborar na busca e identificação de mulheres que se encontram desaparecidas no contexto de redes de tráfico na Argentina. $O$ projeto não só está colaborando na formação de um registro de mulheres desaparecidas (ACCT e PROTEX, 2014), como também tem proposto a elaboração de um banco genético de amostra de mulheres encontradas mortas que ingressaram nos necrotérios como "NN", e familiares de possíveis vítimas de tráfico. Além disso, ainda que lentamente, a equipe de investigação tem começado a escavar lugares de exploração e alguns outros contextos, não só com o propósito de buscar os corpos de possíveis vítimas, mas também de conhecer as condições de vidas nesses lugares (ACCT, 2014).

Outro ponto que não quereremos deixar de considerar são as formas em que os arqueólogos têm se referido ao cenário político onde de desenvolveu nosso trabalho. A participação em 
muitos projetos depende da articulação com distintas instâncias estatais, enquanto os sítios se integram na órbita municipal, provincial, nacional, etc. A maioria dos trabalhos omite falar sobre o vínculo com os governos vigentes, e quando o fazem referem-se a um cenário de consenso. O certo é que muitos projetos se encontram envolvidos em cenários de tensão. $\mathrm{O}$ tema da ditadura tem sido excessivamente apropriado e manipulado por algumas autoridades, essa associação estimula e torna preocupante, o desinteresse por parte da cidadania. Por outra parte, é importante notar que algumas autoridades tinham pouco ou nenhum interesse no tema, suspendendo projetos, limitando financiamentos, etc. (SALERNO e ZARANKIN, 2015). Sempre é difícil falar sobre o presente, porém, sem dúvida, suas dificuldades são algo que não devemos negar e nem ocultar.

\section{PALAVRAS FINAIS}

Ainda que cada contexto apresenta suas próprias particularidades, o caso argentino permite por seu caráter pioneiro, abundância e diverso de trabalhos - aproximarmos de algumas características gerais que haviam adquirido (ou estão adquirindo) as arqueologias das ditaduras em diversos países da América do Sul. Entre elas encontramos uma sorte de trajetórias que levam desde a busca dos desaparecidos, passando pela abordagem dos centros de detenção, até a discussão sobre as narrativas que os próprios arqueólogos ajudaram a modelar. Sem dúvidas, a experiência adquirida ao longo de 30 anos, oferece aos colegas da região (e inclusive de outros contextos) ferramentas para refletir sobre as formas que pretendem desenvolver seus estudos.

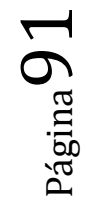
Ernesto Sábato (2000) escreveu "si nos cruzamos de brazos seremos cómplices de un sistema que ha legitimado la muerte silenciosa”. Há algum tempo a arqueologia sul-americana 
iniciou um processo para deixar para trás o lugar de distância e comodidade que a caracterizava, assumindo uma posição ativa frente aos desafios apresentados pelo passado recente e traumático da região. Observamos o crescimento dos trabalhos interessados pelas ditaduras e suas consequências, somos otimistas com o amadurecimento alcançado. Entretanto, ainda que tenhamos avançado bastante, ainda faltam muitos desafios para enfrentarmos, quais sejam: que os organismos de ciência e técnica apoiem as investigações sobre o tema, que nossos próprios trabalhos não emascarem a diversidade e complexidade dos processos abordados, que as arqueologias das ditaduras dialoguem com outras causas de direitos humanos, etc. Da nossa parte, sem dúvida, não podemos desenvolver outro que não um trabalho sempre em marcha.

\section{AGRADECIMIENTOS}

Ao Instituto Multidisciplinario de Historia y Ciencias Humanas - CONICET, e ao Departamento de Antropología e Arqueologia - UFMG. À María Celeste Perosino pelos dados compartilhados. A Pedro Paulo Funari e Rita Juliana Polini, pelo convite para participar da II semana de Arqueologia da Unicamp. A Fernanda Codevilla pela sua ajuda em traduzir este artigo para o português.

\section{BIBLIOGRAFÍA}

ACCIONES COORDINADAS CONTRA LA TRATA -ACCT (2014): [http://acctlatam.org/ Data ๙ da consulta: 15/03/2015]. 
ACCIONES COORDINADAS CONTRA LA TRATA -ACCT- y PROCURADURÍA DE TRATA Y EXPLOTACIÓN DE PERSONAS -PROTEX (2014): Desaparición en democracia. Informe acerca de la búsqueda de personas entre 1990-2013 [http://www.mpf.gob.ar/protex/files/2015/02/Informe-desaparici\%C3\%B3n-en-democracia.pdf Data da consulta: 15/03/2015].

ÁLVAREZ, J. (2007): Derecho internacional y transiciones a la democracia y a la paz. Hacia un modelo para el castigo de los crímenes pasados a través de la experiencia iberoamericana.Parthenon. Madrid.

AVELAR, I. (1999): The untimely present: Postdictatorial Latin American fiction and the task of mourning.Duke University Press. Durham.

BIANCH, S., BASTER, J., BLUHN, S., BRUGÉ, L., CALAMARI, M., CASADEY, M., COMPAÑY, G., GONZÁLEZ, G., GONZÁLEZ, L., HUSS, M., LOJA, F., OVANDO, L., POGNANTE, P., QUEMADA, L., RODA, L., ROMÁN, R., RUBIO, J., SILVA, M., SULICH, K., TOVO, M. (2012) "De las identidades políticas... A la construcción de la memoria colectiva". En: ZARANKIN, A., SALERNO, M. y PEROSINO, MC. (Eds.), Historias desaparecidas. Arqueología, memoria y violencia política. Encuentro. Córdoba: 91-100.

BIANCHI VILLELLI, M. y ZARANKIN, A. (2003): Arqueología como memoria. Intervenciones arqueológicas en el centro clandestino de detención y tortura "Club Atlético". Ms. en archivo. Disponible en Dirección General de Derechos Humanos, Gobierno de la Ciudad Autónoma de Buenos Aires. Buenos Aires.

CENTRO POPULAR DE LA MEMORIA (2003): Proyecto de investigación. Antropología política del pasado reciente: Recuperación y análisis de la memoria histórico-política; Rosario (1955-1983). Ms. en archivo. Disponible en Centro Popular de la Memoria. Rosario. 
COHEN SALAMA, M. (1992): Tumbas anónimas. Informe sobre la identificación de restos de víctimas de la represión ilegal. Equipo Argentino de Antropología Forense. Catálogos. Buenos Aires.

CONADEP (1984): Nunca más. Informe de la Comisión Nacional Sobre la Desaparición de Personas. Eudeba. Buenos Aires.

DIRECCIÓN DE DDHH/MUNICIPIO DE MORÓN (2002-2003/2006-2008). Proyecto Mansión Seré. Informes de gestión. Municipio de Morón. Morón.

EQUIPO ARGENTINO DE ANTROPOLOGÍA FORENSE -EAAF (2008): Latin American Initiative for the Identification of the "Disappeared" (LIID). [http://eaaf.typepad.com/iniciativa_en/ Data da consulta: 10/10/2012].

FAULK, K. (2013): In the wake of neoliberalism. Citizenship and human rights in Argentina. Stanford University Press. Stanford.

FEDERACIÓN ESTATAL DE FOROS DE MEMORIA (2009): Campaña de recogida de firmas "Sin justicia no hay memoria". No al orotocolo de exhumaciones de la Junta de Andalucía [http://www.foroporlamemoria.info/2009/12/campana-de-recogida-de-firmas-sin-justicia-no-haymemoria/. Data da consulta: 10/10/2012].

FERNÁNDEZ MOORES, L. (2006): Un relevamiento de la Secretaría de Derechos Humanos para las Naciones Unidas. Unas 500 cárceles clandestinas, en el mapa de la represión de la dictadura. [http://edant.clarin.com/diario/2006/08/06/elpais/p-01101.htm Data da consulta: 10/10/2012].

FOUCAULT, M. (1977): Vigilar y castigar. Siglo Veintiuno. Madrid.

FUNARI, P., ZARANKIN, A. y SALERNO, M. (2009): "Archaeology, dictatorship, and repression in world context. The Latin American case (1960s-1980s). En FUNARI, P., ZARANKIN, A. y M. SALERNO (Eds.), Memories from darkness. Archaeology of repression and resisitance in Latin America (1960s-1980s). Springer. New York: XI-XXIII.

(๐ Rev. Arqueologia Pública

\begin{tabular}{l|l} 
Campinas, SP & v.
\end{tabular}

No.()

p.72-98 $/ 2015$

ISSN 2237-8294 
GILL, L. (2004): The School of the Americas: Military training and political violence in the Americas. Duke University Press. Durham.

GOFFMAN, E. (2003): Estigma. La Identidad Deteriorada. Amorrortu. Buenos Aires.

LA NACIÓN (2005a): Texto completo de la ley de Punto Final. [http://www.lanacion.com.ar/712959-texto-completo-de-la-ley-de-punto-final. Data da consulta: 10/10/2012].

LA NACIÓN (2005b): Texto completo de la ley de Obediencia Debida [http://www.lanacion.com.ar/712961-texto-completo-de-la-ley-de-obediencia-debida. Data da consulta: 10/10/2012].

LONGONI, A. y BRUZZONE, G. (2008): Introducción. En LONGONI, A. y BRUZZONE, G. (Eds.), El siluetazo. Adriana Hidalgo. Buenos Aires: 5-60.

MAIRA, L. (1990): "El estado de seguridad nacional en América Latina". En GONZÁLEZ, P. (Coord.), El estado en América Latina. Teoría y práctica. Siglo Veintiuno. México DF: 108-130. MALCONTENT, P. y HEPPING, K. (2009): "Luis Moreno Ocampo". En: FORSYTHE, D. (Ed.), Encyclopedia of Human Rights. Oxford University Press. Oxford y New York: 8-11.

MCSHERRY, P. (2002): "Tracking the origins of a state terror network: Operation Condor". Latin American Perspectives, 29 (1): 36-60.

MEMORIA ABIERTA (n/d). Vestigios. Un ensayo de transmisión a través de los objetos. [http://www.memoriaabierta.org.ar/vestigios/proyecto.html Fecha de consulta: 10/10/2014].

NAVARRETE, R. (2006). Rayando tras los muros: Grafiti e imaginario político-simbólico en el Cuartel San Carlos (Caracas, Venezuela). En FUNARI, P. y ZARANKIN, A. (Eds.), Arqueología de la represión y resistencia en América Latina (1960-1980). Brujas, Córdoba: 39-

ᄂ) 66. No.() \begin{tabular}{l|l} 
p.72-98 & $/ 2015$
\end{tabular} ISSN 2237-8294 
NILSON, C. (1998): Operación Cóndor. Terrorismo de estado en el Cono Sur. Lholé-Lumen. Buenos Aires.

PEROSINO, M.C. (2012). Umbral. Praxis, ética y derechos humanos en torno al cuerpo muerto. Tesis de doctorado. Facultad de Filosofía y Letras, Universidad de Buenos Aires.

RICO, J. (1997): Justicia penal y transición democrática en América Latina. Siglo XXI Editores. México DF.

SÁBATO, E. (2000): La resistencia. Seix Barral. Barcelona.

SALADO, M. y FONDEBRIDER, L. (2008): "El desarrollo de la antropología forense en Argentina". Cuadernos de Medicina Forense, 14 (53-54): 213-221.

SALERNO, M. (2007): “'Algo habrán hecho...' La construcción de la categoría 'subversivo' y los procesos de remodelación de identidades a través del cuerpo y el vestido (Argentina, 19761983)". Revista de Arqueología Americana, 24: 29-65.

SALERNO, M. y ZARANKIN, A. (2015): "Discussing the spaces of memory in Buenos Aires. Official narratives and the challenges of site management". En RUIBAL, G. y G. MOSHENSKA (Eds.), Ethics and the archaeology of violence.Springer. New York: 89-112.

SALERNO, M., ZARANKIN, A. y PEROSINO. M.C. (2012): "Arqueologías de la clandestinidad: Una revisión de los trabajos efectuados en centros de detención clandestinos durante la última dictadura militar en Argentina". Revista Universitaria de Historia Militar, 2: 49-84.

SOMIGLIANA, M. y OLMO, D. (2002). “¿Qué significa identificar?” Encrucijadas, 15: 22-35.

UNITED NATIONS, (2006): International Convention for the Protection of All Persons from Enforced Disappearance [http://www.unhcr.org/refworld/docid/47fdfaeb0.html Data da consulta: 28/09/2009]. 
UNIVERSIDAD NACIONAL DE CÓRDOBA (2007). "Las marcas del pasado". Al Filo 3(16). [http://www.ffyh.unc.edu.ar/alfilo/anteriores/alfilo-16/investigacion.htm Data da consulta: 10/10/2014].

WEISSEL, M. (2002): Informe Final Investigación Arqueológica. Ms. en archivo. Disponible en Secretaría de Obras y Servicios Públicos, Gobierno de la Ciudad Autónoma de Buenos Aires, Buenos Aires.

WRIGHT, T. (2007): State terrorism in Latin America: Chile, Argentina, and international human rights. Rowman and Littlefield. Lanham.

ZARANKIN, A. y NIRO, C. (2009). "La materialización del sadismo: Arqueología de la arquitectura de los centros clandestinos de detención de la dictadura militar argentina (19761983)". En: FUNARI, P. y ZARANKIN (Eds.), Arqueología de la represión y resistencia en América Latina (1960-1980). Encuentro. Córdoba: 159-182.

ZARANKIN, A. y SALERNO, M. (2012): “'Todo está guardado en la memoria...' Reflexiones sobre los espacios para la memoria de la dictadura en Buenos Aires (Argentina)". En ZARANKIN, A., SALERNO, M. y PEROSINO, M.C. (Eds.), Historias desaparecidas. Arqueología, memoria y violencia política. Encuentro. Córdoba, 143-171. 


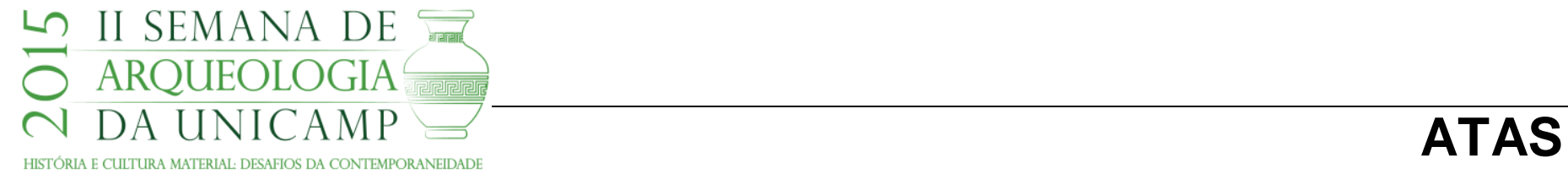

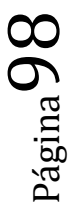

\begin{tabular}{|l|l|l|l|l|l|l}
\hline (C) Rev. Arqueologia Pública & Campinas, SP & v. & No.() & p.72-98 & /2015 & ISSN 2237-8294
\end{tabular} 